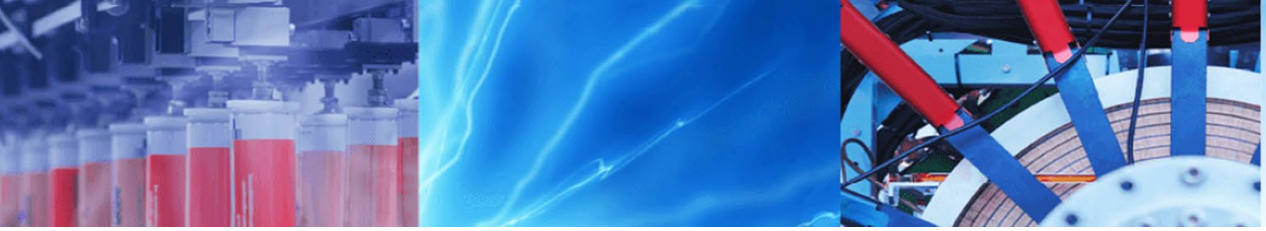

Research Article

\title{
Rheological, EMI and corrosion properties of epoxy coating with nanoparticle and conductive carbon black
}

\author{
Alan A. P. O. Amorim ${ }^{1} \cdot$ Marcia G. Oliveira $^{2} \cdot$ Mauricio C. Mancini $^{3} \cdot$ Alex S. Sirqueira $^{1,4}$
}

Received: 15 August 2020 / Accepted: 19 January 2021 / Published online: 28 January 2021

(C) The Author(s) 2021 OPEN

\begin{abstract}
The purpose of this paper was determining the effects of two nanoparticles additions in a commercial epoxy coating system on rheology characterization. Two kinds of hybrid organic-inorganic silicates (benzytallowdimethylammonium salts with bentonite) were studied, APA, with $C_{14-16}$ organic chain and, $\mathrm{HT}$, with $\mathrm{C}_{2-4}$ organic chain. $A 2^{2}$ factorial design, with two categorical nanoparticules factors was applied. The experimental data of viscosity were fit to three different rheological constitutive models: Herschell-Bulkley, Carreau-Yasuda and Cross. The best fit was obtained by HerschelBulkley model. The APA nanoparticle had substantial changes in yield stress values, but no effect was observed when HT had been isolated. Two thixotropic models were analyzed for the epoxy system, and the better performance was observed for the model with two rheological parameters. The presence of nanoparticule in epoxy coating reduced around $40 \%$ the recovery time. The addition of nanoparticules changes the rheological properties of a commercial coating. The X-Rays Diffraction analyses were done to observe the dispersions degree and exfoliations in the epoxy system. The crystalline peak of nanoparticles had lost for all coating formulations. The electromagnetic interference shielding attenuation was $60 \%$ in the formulations with high content of both nanoparticles. The APA and HT improved hence, the anticorrosion performance of the epoxy coating for $720 \mathrm{~h}$ in chloride solution. Corrosion resistance had the best performance in the coating with high concentration of carbon black and nanoparticles.
\end{abstract}

Keywords Epoxy coating $\cdot$ Nanoparticle $\cdot$ Rheology $\cdot$ Corrosion

\section{Introduction}

Epoxy coatings are widely used for corrosion switch of metallic substrates because of low cost and efficiency in corrosive environments such as seawater, acids, alkali and others. However, many environmental factors (temperature, UV and oxygen) may cause degradation and thus affect the durability of the coated systems. Many studies have been done in order to evaluate the performance under natural or artificial ageing [1-3].
Commercial epoxy coating formulations are complex because there are many compounds, like a mixture of binder, solvent, fillers, pigments and others additives. It is difficult to evaluate only one answer, like the polymeric material in a commercial coating. But, to improve paint technologically, sometime is necessary modifier commercials coatings, adding new fillers, polymer or additives [4-6]. Then, it is important to analyze the end effect. The best way to evaluate news formulations in petrochemical, coating industries and others applications is the statistical data, called the design of

$\triangle$ Alex S. Sirqueira, assirqueira@gmail.com | ${ }^{1}$ Laboratório de Engenharia de Polímeros E Aplicações Industriais, Programa de Pós-Graduação Em Ciência E Tecnologia de Materiais, Centro Universitário Estadual da Zona Oeste- UEZO, Avenida Manuel Caldeira de Alvarenga 1203, Campo Grande, Rio de Janeiro 23070200, Brasil. ${ }^{2}$ Instituto Nacional de Tecnologia, Rio de Janeiro, Brasil. ${ }^{3}$ Universidade Federal Rural Do Rio de Janeiro, Rio de Janeiro, Brasil. ${ }^{4}$ Programa de pós-graduação em Química, Instituto de Química, Universidade Do Estado Do Rio de Janeiro, Rio de Janeiro, Brasil. 
experiment (DOE) $[7,8]$. The decisions (or end effects) of DOE are interconnected, which is the advantage. The appropriate statistical methods for analyzing the data depend on the measurement scale chosen and experimental design [9].

It is very common in nanotechnology, especially in polymer technology, the use of hybrid organic-inorganic system [10]. These nano-structures have dispersive layered silicates in nanoscale, and are very promising for development of new products. Nano hybrids have improved mechanical and thermal stability, solvent uptake resistance and self-extinguishing behavior. The additions of nano filler can improve the commercial coating, giving better properties, like corrosion resistance. The corrosion is a great problem in metallic materials, although there are many kinds of anti-corrosion coating with epoxy, acrylic and other polymers resins [11]. The coating aging and environment effects reduce the protective effect, and it is very expensive to repair petrochemical plant, navies, aircraft, tanks and others. Then, the use of new nano additives can improve the protective coating, e.g., conductive fillers, metal powder, conductive polymer and carbon black[3].

In our previous studies, commercial acrylic paint with conductive carbon black were studied, to modify the original paint characteristic and obtain a clear comprehension of the filler influence on paint rheology [12].

The aim of this study is evaluation the end effects of the modification in a commercial epoxy coating, using two kinds of nano hybrid organic-inorganic silicate. The methodology was done using a 2-level full factorial design with two chosen factors related to the nanoparticles design.

\section{Experimental}

\subsection{Materials}

A bi-component commercial epoxy system, epoxy resin/ filler/titanic oxide (component $A$ ) and polyamide (component B), commercialized from União Química do Brasil, grade name JUMBO (volume solids $=80 \%$, filler $=32 \%$, $\left.\mathrm{TiO}_{2}=25 \%, \mathrm{VOC}=170 \mathrm{~g} / \mathrm{L}\right)$, was used as a polymeric matrix. Conductive Carbon Black (CB) (XC72) was supplied by Cabot Carbon Ltd. The organoclay used in this project was organophilic montmorillonite hybrid organic-inorganic silicates (benzytallowdimethylammonium salts with bentonite) were studied, under the trade name of Claytone APA and HT APA, with $\mathrm{C}_{14-16}$ organic chain and, $\mathrm{HT}$, with $\mathrm{C}_{2-4}$ organic chain from Southern Clay Product Inc. (Gonzales, Texas). Figure 1 presents the modified silicate APA and $\mathrm{HT}$. The percentage of organic content was $24 \%$.

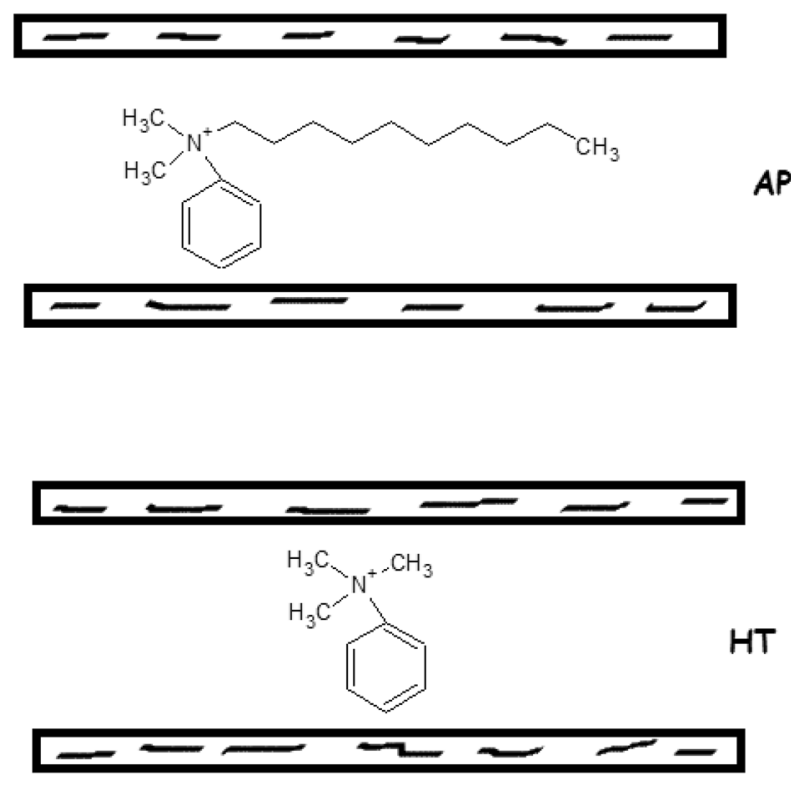

Fig. 1 The structures of benzytallowdimethylammonium salts (APA and $\mathrm{HT}$ )

Table 1 The formulations of epoxy coating

\begin{tabular}{llllll}
\hline Sample & CB (gr.) & HT (gr.) & APA (gr.) & HT & APA \\
\hline Epoxy & 0 & 0 & 0 & $*$ & $*$ \\
1 & 1.0 & 0.5 & 0.5 & -1 & -1 \\
2 & 1.0 & 1.5 & 0.5 & +1 & -1 \\
3 & 1.0 & 0.5 & 1.5 & -1 & +1 \\
4 & 1.0 & 1.5 & 1.5 & +1 & +1 \\
5 & 1.0 & 1.0 & 1.0 & 0 & 0 \\
\hline
\end{tabular}

\subsection{Preparation of the paint formulation}

Statistical analysis full factorial Completely Randomized Design (CRD) was used to study the effect of HT and APA in epoxy coating. A 2-level full factorial design with 2 factors was selected. The factors were continuous amounts of nanoparticles. Thus, a 5-level full factorial experimental design, where each factor was investigated at two levels (low and high), was produced. Each factor level and type was chosen based on preliminary experiments. Additionally, a center point was also incorporated into the design to detect the possible curvature in the fitted data, Table 1.

The methodology is described in Fig. 2. Epoxy coatings with different nanoparticles amounts, and carbon black, were obtained by dispersing the components in a mechanical stirring, at $1500 \mathrm{rpm}$ for $10 \mathrm{~min}$. After that, the coating was ultrasound dispersed for $10 \mathrm{~min}$. The formulations are shown in Table 1. The commercial epoxy

\section{SN Applied Sciences}




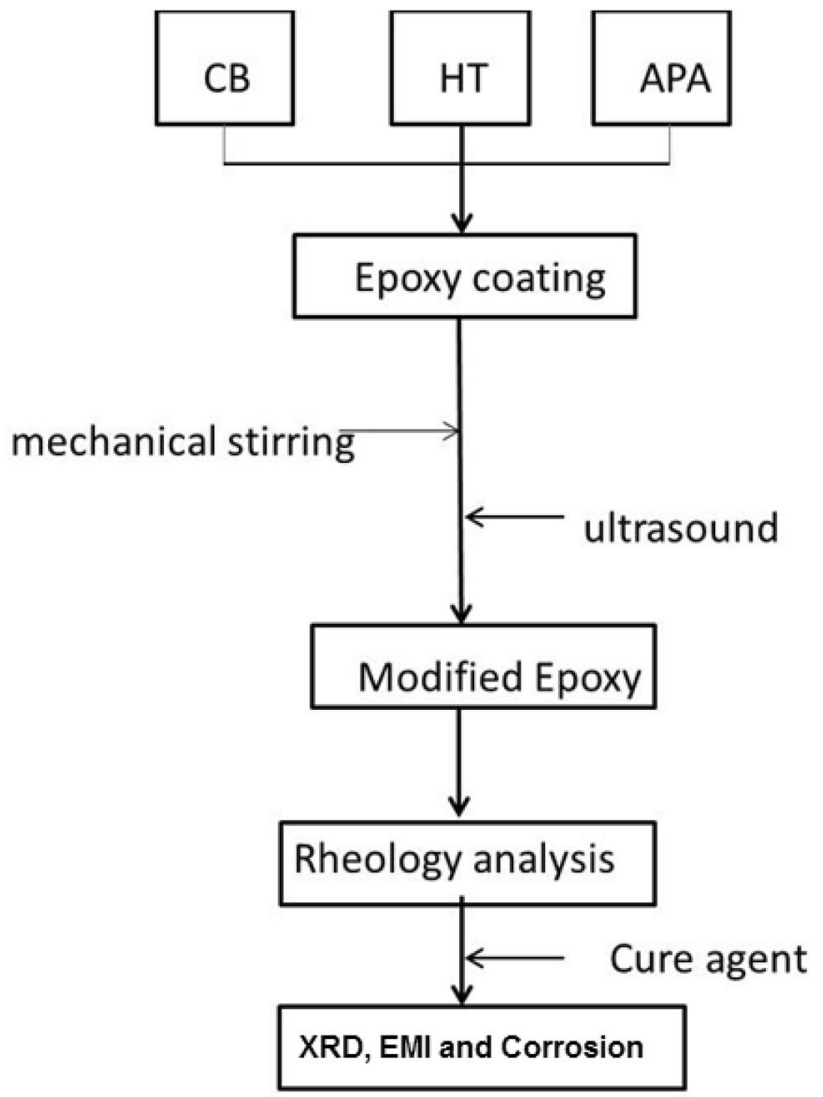

Fig. 2 Methodology

coating is supplied in two containers where a unit compound " $\mathrm{A}$ " is the base (epoxy resin with additives) and " $\mathrm{B}$ " is the curing agent (polyamide) in a weight proportion of $4: 1(A: B)$. All components were mixed in ultrasound for $10 \mathrm{~min}$. The stainless substrates having dimensions $50 \times 50 \times 0.5 \mathrm{~cm}$, were degreased with acetone and dried by using compressed air.

The coating was spread on the stainless substrates using a spiral bar applicator, and cured using the following protocol: $24 \mathrm{~h}$ at $25^{\circ} \mathrm{C}$ and a post-curing at $60^{\circ} \mathrm{C}$ for 30 min. Finally, a dry thickness of $250 \pm 12 \mu \mathrm{m}$ was obtained.

\subsection{Characterization and testing}

All rheological measurements were performed in a stress controlled Rheometer (DHR TA Instruments, USA), using parallel plates with $40 \mathrm{~mm}$ diameter, $25^{\circ} \mathrm{C}$ and gap distance of $1 \mathrm{~mm}$. For the steady-shear flow measurements, a shear rate $(\dot{\gamma})$ from 0.1 to $100 \mathrm{~s}^{-1}$ was applied, and the shear stress $(\tau)$ and apparent viscosity $(\eta)$ were recorded as a function of shear rate. Three rheological models were used to describing the behavior of epoxy system. The data were fitted using R software (R Core Team, 2018).
The Herschel-Bulkley model is given by

$\eta=\frac{\tau_{0}}{\dot{\gamma}}+K(\dot{\gamma})^{n-1}$

where $\eta$ is apparent viscosity (Pa.s), $K$ is consistency coefficient $\left(P a . s^{n}\right), \dot{\gamma}$ is shear rate $\left(s^{-1}\right), \tau_{0}$ is the yield stress $(\mathrm{Pa})$ and $\mathrm{n}$ is the flow behavior index (dimensionless). For stresses bellow the yield stress, the Herschel-Bulkley model predicts $\dot{\gamma}=0$.

The apparent viscosity obtained with the Carreau-Yasuda model is

$\eta=\eta_{0}\left(1+(\lambda \dot{\gamma})^{a}\right)^{\frac{n-1}{a}}$

where $\eta_{0}$ is the viscosity at zero shear rate and $\lambda$, a and $n$ are fitted parameters.

The Cross model is given by

$\eta=\frac{\eta_{0}}{1+(\lambda \dot{\gamma})^{1-n}}$

where $\eta_{0}$ is the viscosity at zero shear rate and $\lambda$ and $n$ are fitted parameters.

It is expected that the Carreau-Yasuda and Cross models have a clear advantage over the Power-Law model, once they can describe the viscosity behavior from the Newtonian plateau at low shear rates to high shear regions with substantial shear thinning.

The application of Three Interval Thixotropy Test (3ITT) was useful to epoxy coating system [13] or inks [14]. The samples were deformed with different shear rate values $\left(1200\right.$ and $\left.1 \mathrm{~s}^{-1}\right)$ at $25^{\circ} \mathrm{C}$. During the first and third intervals, the samples were sheared at low shear rate $1 \mathrm{~s}^{-1}$, and second interval was performed with $200 \mathrm{~s}^{-1}$. In the first and second part of study, the sample was deformed for $60 \mathrm{~s}$ and in the third, for $3500 \mathrm{~s}$.

For dynamic viscoelastic measurements, the linear viscoelastic range of the epoxy/nano particle/carbon black dispersions was determined with a frequency sweep $(0.01-300 \mathrm{~Hz})$ at a fixed deformation of $1 \%$. The storage modulus $\left(G^{\prime}\right)$, loss modulus $\left(G^{\prime \prime}\right)$, loss tangent (tan $\left.\delta=G^{\prime \prime} / G^{\prime}\right)$ and complex viscosity $\left(\eta^{*}\right)$ as a function of angular frequency $(\omega)$ were continuously determined during the test. All rheological measurements were performed in triplicate and the average values of effectively overlapping traces were reported.

$X$-ray diffraction spectra for the nanoparticle and epoxy coatings were obtained by using a Rygaku $X$-ray diffractometer using $\mathrm{Cu}$, a radiation of wavelength $1.54 \AA$ and continuous scan speed of $0.045 / \mathrm{min}$. Diffraction data were recorded at room temperature, in the range of $1^{\circ} \leq 2 \theta \leq 12$.

Thermal stability of the materials was studied by thermo-gravimetric analysis (TGA) using a TA Instruments 
TGA with weight changes measured as a function of temperature using scan rates of $10^{\circ} \mathrm{C} / \mathrm{min}$.

The electromagnetic interference shielding effectiveness (EMI-SE) in the $\mathrm{X}$-band waveguide range

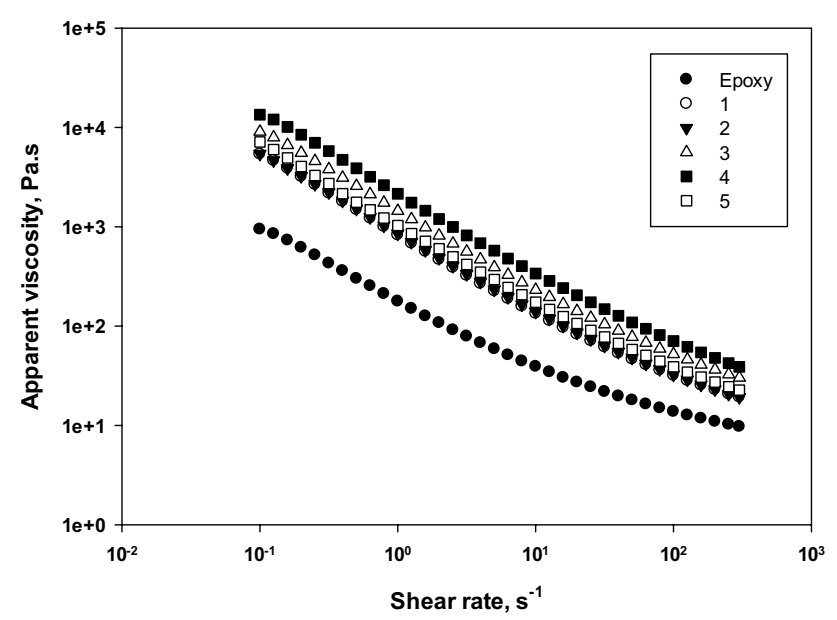

Fig. 3 Apparent viscosity curves at $25^{\circ} \mathrm{C}$
(8.2-12.4 GHz) was measured using a network analyzer type N5230L PNA-L equipped with rectangular waveguide.

The corrosion resistance measurements were conducted after 30 days immersion in $3.5 \mathrm{wt} \% \mathrm{NaCl}$ solution.

\section{Results and discussion}

\subsection{Rheological measurement}

Rheological studies are used to explain and evaluate the deformation and flow behavior of materials, like drilling fluids, polymers, foods, coatings and others. Paints and coatings ought to optimize their final use, which for coatings includes leveling, pigment dispersibility, sag resistance and film thickness, all of which depend on the coating rheological behavior. Figure 3 presents the flow curves, where the apparent viscosities were determined as a function of shear rate, for the epoxy coating prepared with different nanoparticles concentrations ( 0.5 to $1.5 \mathrm{phr}$ ) at $25^{\circ} \mathrm{C}$. Table 2 presents the fitted rheological parameters for the Herschel-Bulkley, Carreau and Cross models. It can

Table 2 Parameters of rheological models a) Herschel-Bulkley, b) Careau-Yasuda and c) Cross

\begin{tabular}{|c|c|c|c|c|c|c|c|c|c|c|c|}
\hline \multicolumn{12}{|c|}{ a) Herschel-Bulkley } \\
\hline Sample & $\tau_{\mathrm{o}}(\mathrm{Pa})$ & $\sigma_{\tau}$ & $p$-value & $\mathrm{K}\left(\mathrm{Pa} . \mathrm{s}^{\mathrm{n}}\right)$ & $\sigma_{k}$ & $\mathrm{p}$-value & $\mathrm{n}$ & $\sigma_{\mathrm{n}}$ & $p$-value & $\mathrm{R}^{2}$ & MRD(\%) \\
\hline Epoxy & 123,900 & 4700 & $<2.10^{-16}$ & 48,990 & 1654 & $<2.10^{-16}$ & 0.7069 & 0.0061 & $<2.10^{-16}$ & 0.9995 & 5.49 \\
\hline 1 & 631,700 & 17,810 & $<2.10^{-16}$ & 166,800 & 8848 & $<2.10^{-16}$ & 0.5978 & 0.0095 & $<2.10^{-16}$ & 0.9986 & 4.02 \\
\hline 2 & 627,100 & 19,320 & $<2.10^{-16}$ & 193,400 & 10,350 & $<2.10^{-16}$ & 0.5718 & 0.0096 & $<2.10^{-16}$ & 0.9985 & 4.19 \\
\hline 3 & 1054,000 & 33,030 & $<2.10^{-16}$ & 333,000 & 18,610 & $<2.10^{-16}$ & 0.5534 & 0.0100 & $<2.10^{-16}$ & 0.9983 & 4.09 \\
\hline 4 & 1514,000 & 44,610 & $<2.10^{-16}$ & 561,900 & 28,610 & $<2.10^{-16}$ & 0.5032 & 0.0090 & $<2.10^{-16}$ & 0.9985 & 3.17 \\
\hline 5 & 754,100 & 25,230 & $<2.10^{-16}$ & 257,300 & 14,370 & $<2.10^{-16}$ & 0.5493 & 0.0100 & $<2.10^{-16}$ & 0.9983 & 4.03 \\
\hline
\end{tabular}

b) Carreau-Yasuda

\begin{tabular}{lllllllllllllll}
\hline Sample & $\eta_{\mathrm{o}}(\mathrm{Pa})$ & $\sigma_{\eta}$ & $\mathrm{p}$-value & $\lambda(\mathrm{s})$ & $\sigma_{\lambda}$ & $\mathrm{p}$-value & $\mathrm{n}$ & $\sigma_{\mathrm{n}}$ & $\mathrm{p}$-value & $\mathrm{a}$ & $\mathrm{a}_{\sigma}$ & $\mathrm{p}$-value & $\mathrm{R}^{2}$ & $\mathrm{MRD}(\%)$ \\
\hline Epoxy & 971,1 & 31,44 & $<2.10^{-16}$ & 9269 & 0.349 & $<2.10^{-16}$ & 0.2496 & 0.0078 & $<2.10^{-16}$ & 9764 & 4335 & 0.0313 & 0.9997 & 22.52 \\
1 & 6323,0 & 318,50 & $<2.10^{-16}$ & 11,330 & 0.641 & $<2.10^{-16}$ & 0.1667 & 0.0032 & $<2.10^{-16}$ & 6021 & 1228 & $2.64 \mathrm{E}-05$ & 1.0000 & 15.77 \\
2 & 6651,0 & 419,50 & $<2.10^{-16}$ & 12.030 & 0,871 & $4,92 \mathrm{E}-15$ & 0.1786 & 0.0032 & $<2.10^{-16}$ & 5270 & 1101 & $3.68 \mathrm{E}-05$ & 1.0000 & 14.32 \\
3 & 9890,0 & 191,40 & $<2.10^{-16}$ & 10.120 & 0.211 & $<2.10^{-16}$ & 0.1723 & 0.0026 & $<2.10^{-16}$ & 6,860 & 0814 & $1,24 \mathrm{E}-09$ & 1.0000 & 13.79 \\
4 & $14,380,0$ & 193,60 & $<2.10^{-16}$ & 9396 & 0.127 & $<2.10^{-16}$ & 0.1572 & 0.0033 & $<2.10^{-16}$ & 6,598 & 0638 & $1,01 \mathrm{E}-11$ & 1,0000 & 13,69 \\
$5^{*}$ & $* *$ & $* *$ & $* *$ & $* *$ & $* *$ & $* *$ & $* *$ & $* *$ & $* *$ & $* *$ & $* *$ & $* *$ & $* *$ & $* *$ \\
\hline
\end{tabular}

\section{C) Cross}

\begin{tabular}{|c|c|c|c|c|c|c|c|c|c|c|c|}
\hline Sample & $\tau_{0}(\mathrm{~Pa})$ & $\sigma_{\tau}$ & $p$-value & $\lambda(\mathrm{s})$ & $\sigma_{\lambda}$ & $p$-value & $\mathrm{n}$ & $\sigma_{n}$ & $p$-value & $\mathrm{R}^{2}$ & MRD(\%) \\
\hline Epoxy & 5286,00 & 1606.00 & $2.39 \mathrm{E}-03$ & $66.43^{*}$ & $34.57^{*}$ & $6.33 \mathrm{E}-02$ & 0.2095 & 0.0255 & 1.76E-09 & 0.9988 & 25.59 \\
\hline 1 & $36,960,00$ & 5485.00 & $1.12 \mathrm{E}-07$ & 74,780 & 16,510 & 7.33E-05 & 0.1278 & 0.0109 & $2.35 \mathrm{E}-13$ & 0.9998 & 19.90 \\
\hline 2 & $39,650,00$ & 5542.00 & $3.38 \mathrm{E}-08$ & 84,780 & 17,730 & $3.49 \mathrm{E}-05$ & 0.1432 & 0.0093 & $<2.10^{-16}$ & 0.9999 & 18.14 \\
\hline 3 & $42,200,00$ & 5286.00 & 3.30E-09 & 42,190 & 8376 & $1.66 \mathrm{E}-05$ & 0,1103 & 0,0146 & $1,05 \mathrm{E}-08$ & 0,9997 & 20.63 \\
\hline 4 & $44,160,00$ & 4582.00 & $4.06 \mathrm{E}-11$ & 23,360 & 4011 & $1.63 \mathrm{E}-06$ & 0,0606 & 0,0198 & 4,38E-03 & 0,9995 & 24.09 \\
\hline $5^{*}$ & $* *$ & $* *$ & $* *$ & $* *$ & $* *$ & $* *$ & $* *$ & $* *$ & $* *$ & $* *$ & $* *$ \\
\hline
\end{tabular}

* Parameters were not significant 
be observed that all formulations present a shear thinning behavior $(n<1)$. The values of flow behavior index (n) range from 0.503 to 0.706 . In general, the shear thinning is produced by deformation and breakage of internal structures under flow. Because of Brownian motion or interactions that induces relative motion of particles, the microstructure can rebuild as flow decreases or stops, and, in some cases, form a space-filling structure network [15, 16]. The continuous decrease of the apparent viscosities is also related to the increased alignment of the constituent macromolecules as the flow develops. In other words, when the suspension is brought to flow, the particles distance increases in the normal direction and decreases in the flow direction. This results in a layered structure that offers less resistance to flow and is dominated by hydrodynamic forces $[17,18]$. Suspensions that tend to form a network at rest would present a more severe shear thinning behavior.

All samples with nanoparticles had large viscosities comparing to commercial epoxy paint, probably due the increase of fillers content. Although the commercial epoxy had fillers in the composition, the presence of $\mathrm{CB}$ and nanoparticles will increase the viscosities. But, to obtain the nanocomposite with differential properties it is necessary the exfoliated clay. When the effects of nanoparticles (APA and $\mathrm{HT}$ ) are isolated, by DOE analysis, the apparent viscosity increased with the APA occurrence (samples 3 and 4). Probably due to the presence of the long organic chain in APA particle, compared with HT particle. Many papers in the literature ratifies that the formation of exfoliated clay nanocomposites is dependent on the nature of the organic chain. Long alkyl chains between the galleries allow new organic species to diffuse between the layers more easily and progressively exfoliate the clay. This works confirms the effect alkly chains. The short chain does not have force to overcome the attractive electrostatic force between the negative charged silicate and the gallery cations. Also, as APA can swell in the matrix, the viscosity will increase. The exfoliated nanocomposite depends on the nature of the alkylammonium-exchanged clay[19]. As APA has long alkly chains, probably the end structure can be more dispersed in the commercial epoxy coating.

Viscous fluids differ from elastic solids due to their incapability to sustain shear stresses without flowing [20]. The viscoelastic materials have both elastic and viscous behavior. Another important class of materials is the one that presents a transition from elastic to viscous behavior, when the material structure changes from a fully structured state to an unstructured one. This transition occurs at a critical stress, called the yield stress [21], and these materials are called elasto-viscoplastic. The yield stress can be estimated from the flow curve of the material, starting from high shear rates to very low shear rates [22]. It can be also obtained by fitting the flow curve to the HerschelBulkley (HB) model. HB model found to be adequate for describing the flow behavior of the epoxy coating because the determination coefficients $\left(R^{2}\right)$ were higher than 0.998 . Recently, Coussout has done a wide discussion about yield stress behavior for elasto-viscoplastic fluids, the explanations proposed that slow flows of yield stress fluids were a kind of extension of plastic flows for very large deformations and without irreversible changes of the structure [15]. Such effects take the form of time evolution of the apparent viscosity in the liquid regime, due to some progressive destructuring. Table 2 shows that the formulations 4 , in high level $(+,+)$, have the largest effect on the yield stress values. But, analyzing carefully, it is clear that the APA had substantial changes in values, while almost no changes were observed when the HT effect is isolated. The long chain in APA can open the layer bentonite structure. It was also observed that the breakdown of the structure in the liquid regime can be high. Table 2 also indicates that increasing nanoparticles concentration cause a considerable non-linear increase in consistency coefficients (K). The consistency coefficient is related to the level of the flow resistance. If $\mathrm{K}$ increases, the apparent viscosity has the same behavior. A consistent trend was observed in $\mathrm{K}$ and $n$ value, depending on the factorial level. In the literature, similar tendency was observed in epoxy coating with nanoparticles $[5,12,23,24]$.

In addition to Herschell-Bulkley model, two other expressions are frequently used for better fitting of data over the entire range and to include the Newtonian plateau at low shear rates. But the fitted parameters for sample 5 are located in singularity regions and the statistical program $\mathrm{R}$ had not converged for that sample. Then, the Cross and Careau-Yasuda model were not considered to describe the DOE experiments used in this study.

The HB response variables (yield stress and consistency coefficient) were chosen to be obtained for each run as a measure of abuse deterrence performance. Variables for the polynomial factorial model were deleted from the model if they had $p$-values greater than 0.05 or kept if their $p$-values were less than or equal to 0.05 . This was done to keep only those factors that have the most significant main effects and interactions $[25,26]$. The HT and APA concentrations and their interactions were evaluated for multilinear equations, but, for this simple experimental set, the polynomial equations presented non-significant coefficients, and the effects of APA and HT on HerschelBulkley rheological parameters are inconclusive, requiring further studies.

Dynamic oscillatory tests are generally used to obtain the viscoelastic response of a material $[27,28]$. The storage and loss moduli were measured as a function of angular frequency $(\omega)$, at $20^{\circ} \mathrm{C}$, and are shown in Fig. 3. As it can 
be observed, there has been a phase transition during the frequency sweep test, and the epoxy coating formulations with nanoparticles present a fairly good tolerance to external forces. This suggests that there are effective physical entanglements. Figure 4 and Table 3 show that the nanoparticle addition changes substantially the crossover (transition) point. Comparison of the crossover values (i.e., where $G^{\prime}=G^{\prime \prime}$ ) of the epoxy between the formulations with nanoparticles indicate that the phase transition occurs in high frequency. The elastic modulus field has a large frequency range, evidencing the entanglements or ionic links in the epoxy coating. As the percentage of APA particles increases, interactions increase because the exfoliation process between long organic chair and epoxy groups is easier, increasing the viscoelastic properties. From Table 3 it can be seen that the crossover values are larger for the formulations with the nanoparticles than that for the epoxy coating, suggesting the stability and the dominant elastic nature of the coating. This is an interesting result that indicates that the coating formulation can present better results, reducing the sagging after dispersion on a substrate as metal. To understand the effect of time during the structure recovery after a force application, the thixotropic analysis was performed.

\subsection{Thixotropy measurements}

Complex fluids with weakly aggregated internal structures often present thixotropic behavior, defined as a flow-induced reversible time-dependent shear-thinning viscous response $[12,20]$. An important criterion of thixotropy is the reversible effect, when the substance is left to rest. Figure 4 presents the 3ITT curves of the epoxy coating samples deformed with different three interval of shear rates $\left(1200\right.$ and $\left.1 \mathrm{~s}^{-1}\right)$. The 3ITT methodology is different from the well-known frequency sweep and

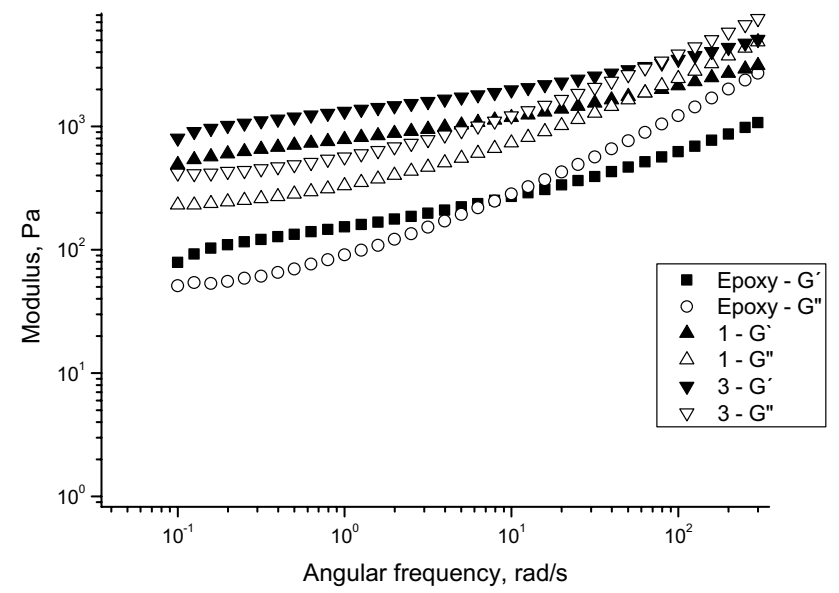

Fig. 4 Viscoelastic modulus for epoxy coating
Table 3 Crossover result in frequency sweep test for epoxy coating

\begin{tabular}{lrr}
\hline sample & $\mathrm{G}^{\prime}=\mathrm{G}^{\prime \prime}$ & \multicolumn{1}{c}{$\omega$} \\
\hline Epoxy coating & 254.97 & 8.33 \\
1 & 1677.89 & 52.31 \\
2 & 1864.00 & 62.56 \\
3 & 3152.30 & 69.96 \\
4 & 4880.28 & 94.09 \\
5 & 2365.69 & 70.81 \\
\hline
\end{tabular}

creep/recovery tests since an instant "shear rate/shear stress" can be applied in non-linear viscoelastic region and deformation can be examined in both LVR and nonLVRs. The purpose here is to break the internal structure of the materials in order to simulate high shear conditions that normally occur during processing and handling of materials like, for example, pumping, instant stirring or shaking. As it can be seen from Fig. $5, \mathrm{G}_{0}$ (initial storage modulus after deformation was applied) values of the samples were found to be lower than $G_{i}^{\prime}$ (storage modulus of the sample prior to the deformation) value, indicating that applied shear rate resulted in deformation of the epoxy samples. In the present methodology, the samples were pre-sheared at $1 \mathrm{~s}^{-1}$ for $120 \mathrm{~s}$, and then the first interval data were collected at $1 \mathrm{~s}^{-1}$ for $60 \mathrm{~s}$. This explains the increase in $G_{i}^{\prime}$ for the epoxy coating modified. The pre-shear could stimulate some destruction in the coating structure, and samples 1 to 5 try to re-build (rest shear time, leading to the increase in the $\mathrm{G}^{\prime}$ curve. However, analyzing the values in the first region of 3ITT curve (rest shear time), between 1 and $60 \mathrm{~s}$, no statistical difference was observed, with values of variation coefficient (CV) lower than 5\%. The storage modulus decreased as shear rate increased. This effect can be attributed to the structure rupture. Decreasing the shear rate (third part of the experiment) resulted in an increase

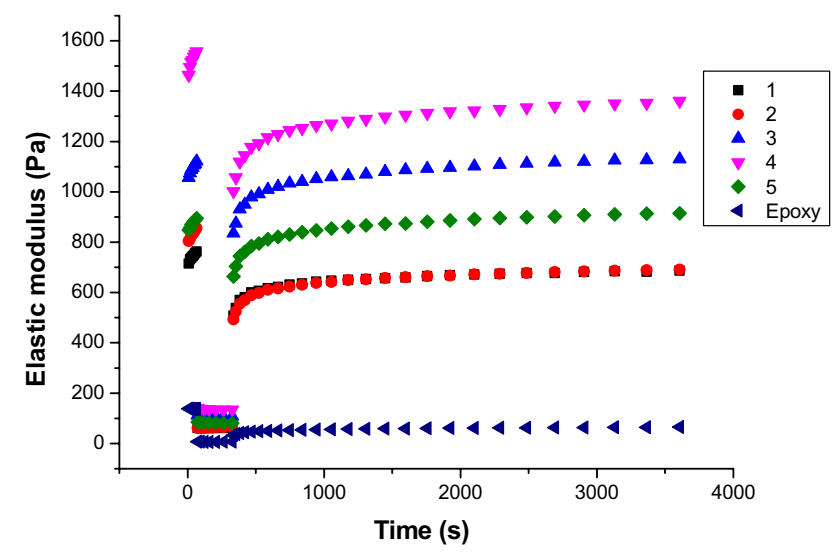

Fig. 5 Thixotropy curves for Epoxy coating blends 
of the storage modulus, but the reached value after this stage was lower when compared to that of the first stage [13]. As the addition of nanoparticle in epoxy coating increases the storage modulus, in the higher shear rate the structure (polymer-nanoparticle) will be destructed. As the gel affinity (polymer-nano) is strong, the recovery phenomenon will be observed. However, for commercial epoxy coating this recovery effect was not observed. In Fig. 5, remarkable differences among the values were observed, which may have resulted from the differences on type and amount of nanoparticles present in each formulation.

Aiming to explain the thixotropy data, two models [Eq. (4) and (5)], were evaluated to describe thixotropic behavior $[13,29]$.

Model I:

$G^{\prime}=G_{o}+\left(G_{\infty}-G_{0}\right)\left(1-e^{-\frac{t}{\tau}}\right)$

where: $G^{\prime}$ is the storage modulus, $G_{0}$ represents the initial $G^{\prime}$ value is the initial storage modulus, $G_{\infty}$ is the storage modulus in the rest shear rate, and $\tau$ is the characteristic restructuring time.

Model II:

$\left[\frac{\left(G_{\infty}-G^{\prime}\right)}{\left(G_{\infty}-G_{o}\right)}\right]^{(1-n)}=(n-1) k t+1$

where: $G^{\prime}$ is the storage modulus, $G_{0}$ is the initial storage modulus at $\mathrm{t}=0 \mathrm{~s}, \mathrm{G} \infty$ is the equilibrium storage modulus as $\mathrm{t} \rightarrow \infty$ (non-structured state), $\mathrm{k}$ is the rate constant of recovery of the sample, and $\mathrm{n}$ is order of structural kinetic model.

As it can be seen in Eqs. 4 and 5, model I is a single parameter model $(\tau)$, and model II has two fitting parameters $(k, n)$. Figure 6 shows the experimental data and the fitted curves for both models. It is possible to observe that the fitted curves obtained with model II are closer to the experimental data, suggesting better description. Tables 5 and 6 present the fitting parameters, the $p$-value, the discrimination coefficient $\left(R^{2}\right)$ and the mean relative deviation (MRD) for each sample, for model I and model II, respectively.

The characteristic restructuring time values are shown in Table 4. All epoxy formulations coating have lower values, which is in accordance with the curves in Fig. 5. The presence of nanoparticule in commercial epoxy reduced the time to recovery. The range reduced around $30-45 \%$ in time that is a good result because the addition of nano changes the properties of commercial coating. Although the fitted curves are not so close to experimental data as desirable, the values of $R^{2}$ are higher than to 0.94 and
MRD are lower than 5.0\%, for Epoxy, and lower 3.0\% for other samples. By statistical criteria, based on $\mathrm{R}^{2}$ and MRD values, model I could be used to describe the curves, if a better model is not available.

Table 5 presents the values of the parameters $k$ and $n$, for model II, and their respective values of $p$-value, $R^{2}$ and MRD (\%). In this case, the fitted curves are much closer to experimental data than observed for model I. The values of $\mathrm{R}^{2}$ are higher than 0.95 and $\mathrm{MRD}$ are lower than $2.4 \%$, for Epoxy, and lower than 1.2\%, for the other samples. In terms of model discrimination criteria, those results indicate that model II describes the curves much better than model I and may be widely used in this kind of study.

\subsection{XRD}

In order to determine the degree of clay exfoliation in the commercial epoxy coating, a XRD study was carried out to find out the interlayer spacing of tactoids in the course of processing. Figure 7 shows the XRD profiles of epoxy coating with and without nanoparticles. In XRD analysis, it can be seen that the nanoparticles APA and HT graphics suggests some level of ordering [30]. The curves have sharp and defined diffraction peaks (4.58 for APA and 2.87 for $\mathrm{HT}$ ), as well as a less significant shift towards the lower diffraction angles, indicative of a certain degree of clay intercalation (HT). There is no diffraction peak for the samples with nanoparticles. Probably the combinations of the two dispersions methodology (ultrasound and ultraturrax) give a good dispersion. This results can suggest the existence of an exfoliate structure for all nano epoxy coating studied, and consequently, the diffraction peaks disappeared [31]. The evidence of exfoliated clay in this situation cannot be confirmed, because the commercial epoxy coating had the same behavior (lost the peak) in the graphic. As the coating is a commercial product with others fillers, the visualization of the intercalated or exfoliated are not precise. The missed characteristic peaks can be related to the effective high shear stress applied during dispersion, expanding the layer space of tactoids [32]. These results can be related to the increase of viscosity on rheological behavior and not only by the exfoliate dispersion.

\subsection{EMI}

For polymer materials at higher EMI waves $(8-12 \mathrm{GHz})$ attenuation is in absorption and reflection parameters. In this regard, conductive fillers, like carbon black, are used in epoxy coating, because had high absorption for EMI attenuation and could help the corrosion protective. Figure 8 presents the total attenuation (absorption and reflection). All samples showed attenuation, specialty in the range of 8-11 GHz. The sample with nanoparticle in high level of CB 
Fig. 6 Fit of rheological models

(1)
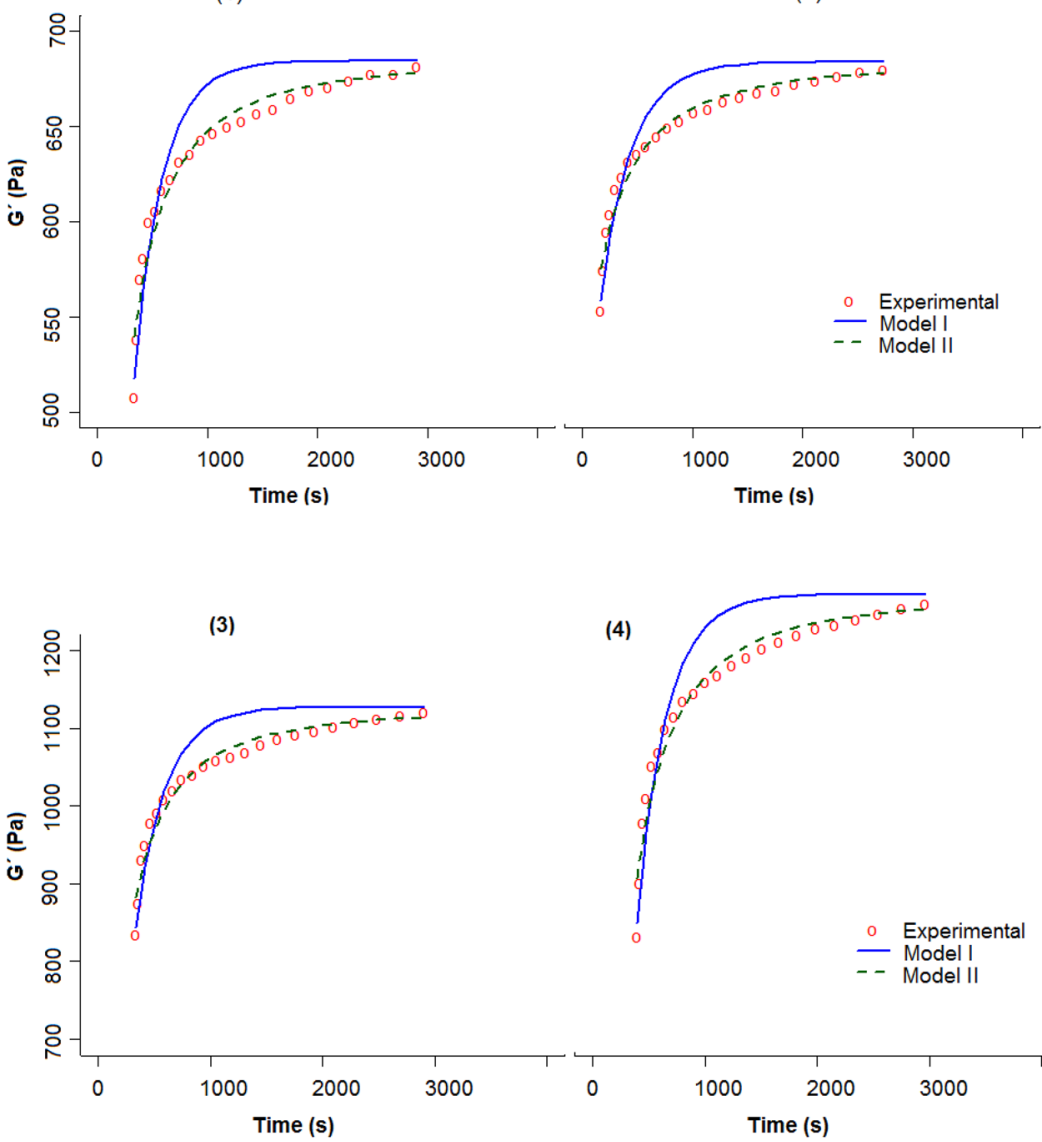

- Model I Model I

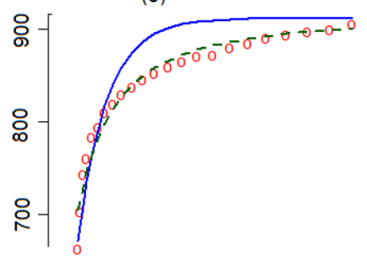

Epoxy

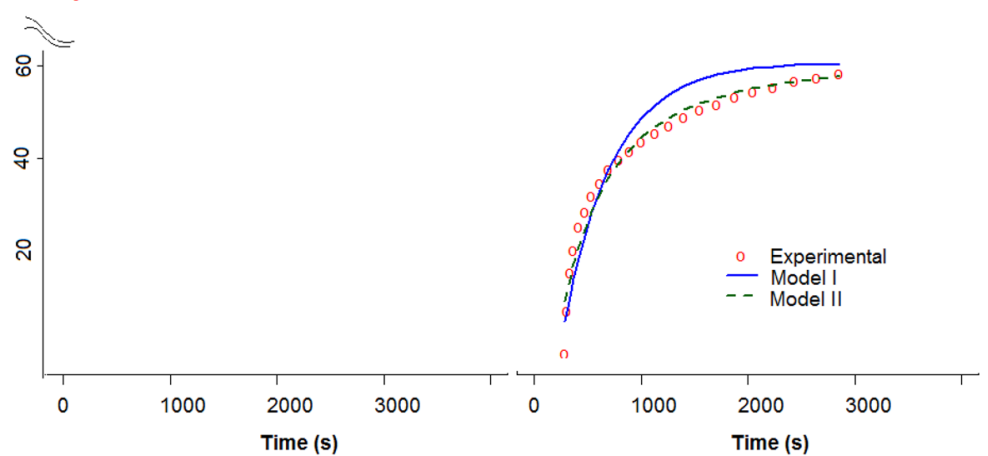

and Nano particles showed the best attenuation, around $55 \%$. The EMI shielding effectiveness depends on so many factories, like concentrations and kind of fillers.[33]. In this study, the increases of carbon black improve the attenuation in the range of $8-11 \mathrm{GHz}$, because had good dispersion in the epoxy coating.

\subsection{Corrosion}

Figure 9 shows the corrosion resistance performance. After 30 days immersions, the samples with high $\mathrm{CB}$ and Nano concentrations exhibited better corrosion resistance. This observation could be linked to the attack of $\mathrm{Cl}^{-}$ions in the

\section{SN Applied Sciences}


Table 4 Rheological parameter for model I

\begin{tabular}{llrlll}
\hline Sample & $\tau(\mathrm{s})$ & \multicolumn{1}{c}{$\sigma_{\tau}$} & $\mathrm{p}$-value & $\mathrm{R}^{2}$ & $\mathrm{MRD}(\%)$ \\
\hline Epoxy & 463.30 & 16.640 & $<2.10^{-16}$ & 0.9592 & 4.26 \\
A1 & 254.70 & 8.858 & $<2.10^{-16}$ & 0.9450 & 2.59 \\
A2 & 279.16 & 10.180 & $<2.10^{-16}$ & 0.9522 & 2.97 \\
A3 & 263.29 & 9.558 & $<2.10^{-16}$ & 0.9473 & 2.73 \\
A4 & 262.19 & 9.470 & $<2.10^{-16}$ & 0.9488 & 2.73 \\
A5 & 271.36 & 10.050 & $<2.10^{-16}$ & 0.9500 & 2.93 \\
\hline
\end{tabular}

surface[34]. This behavior resulted from water and chloride ions diffusion into the coating system.

\section{Conclusions}

In this work, two kinds of nanoparticles were added in a commercial epoxy coating with the goal of dispersing effectively the APA and HT nanoparticles. The mixtures were successfully produced via physical mixture using a factorial design of experiment $2^{2}$. The applied tension is one of the most important factors to obtain nanocomposites with better clay dispersion. In this study ultrasound and mechanical dispersion were used to disperse the nanoparticle.

The nanoparticle APA increased more the apparent viscosity. The best fit for viscosity curve was obtained with the Herschell-Bulkley model. Based on model discrimination criteria, the Herschell-Bulkley model presented the best fit for all samples studied in this research, with $\mathrm{R}^{2}$ higher than 0.998 and RMD lower than 5.50\%.

The analysis of 3ITT appears to be an effective tool to simulate and analyze thixotropic effect of real pumping and instant stirring processes during production and application of coating. Two thixotropic models were analyzed, and the better performance was observed for the two parameters model. In terms of thixotropic description, Model II described the recovering phase with $\mathrm{R}^{2}$ higher than 0.95 and RMD lower than $2.50 \%$, which indicates that this model can be used to predict thixotropic behavior of samples similar to those evaluated in this work.

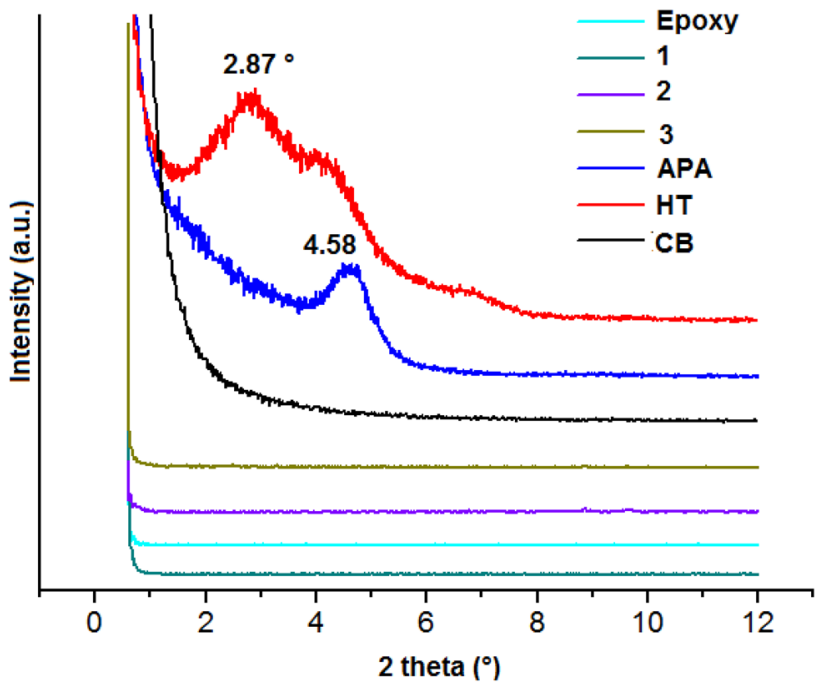

Fig. 7 XRD for epoxy coating

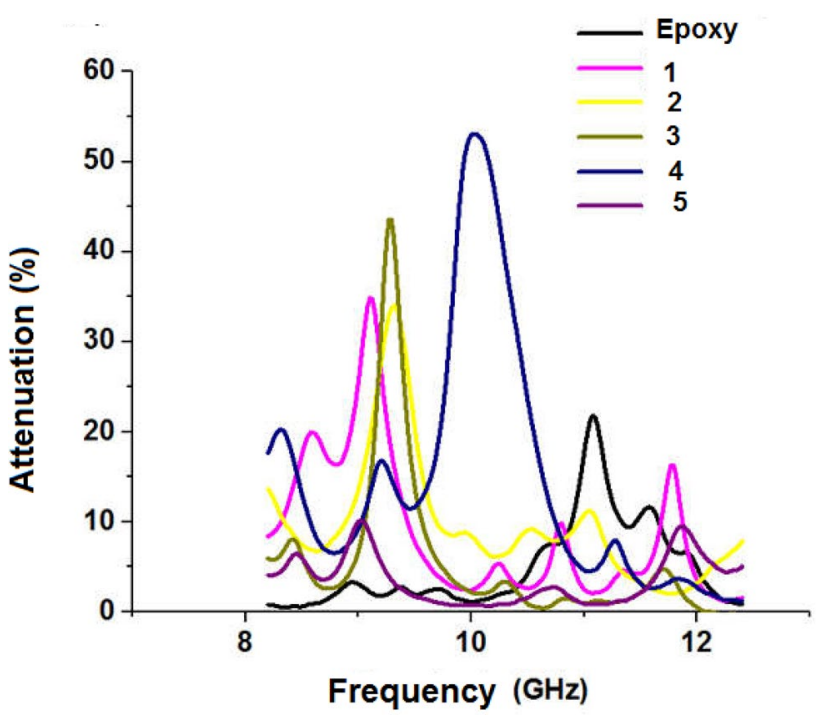

Fig. 8 EMl attenuation
Table 5 Rheological parameters for model II

\begin{tabular}{lllllllll}
\hline Sample & $\mathrm{k}(1 / \mathrm{s})$ & $\sigma_{\mathrm{k}}$ & $\mathrm{p}$-value & $\mathrm{N}$ & $\sigma_{\mathrm{n}}$ & $\mathrm{p}$-value & $\mathrm{R}^{2}$ & $\mathrm{MRD}(\%)$ \\
\hline Epoxy & $2.85 \mathrm{E}-03$ & $1.88 \mathrm{E}-04$ & $8,47.10^{-13}$ & 1,4047 & 0.0793 & $4,19.10^{-14}$ & 0.9645 & 2.36 \\
A1 & $6.53 \mathrm{E}-03$ & $5.46 \mathrm{E}-04$ & $7,81.10^{-11}$ & 1,5259 & 0.0710 & $8,78.10^{-16}$ & 0.9571 & 1.13 \\
A2 & $5.93 \mathrm{E}-03$ & $4.41 \mathrm{E}-04$ & $8,71.10^{-12}$ & 1,5526 & 0.0664 & $<2.10^{-16}$ & 0.9646 & 1.16 \\
A3 & $6.47 \mathrm{E}-03$ & $5.09 \mathrm{E}-04$ & $2,55.10^{-11}$ & 1,5596 & 0.0675 & $<2.10^{-16}$ & 0.9620 & 1.15 \\
A4 & $6.48 \mathrm{E}-03$ & $5.22 \mathrm{E}-04$ & $3,87.10^{-11}$ & 1,5569 & 0.0689 & $3,27.10^{-16}$ & 0.9602 & 1.14 \\
A5 & $6.29 \mathrm{E}-03$ & $4.76 \mathrm{E}-04$ & $1,22.10^{-11}$ & 1,5724 & 0.0660 & $<2.10^{-16}$ & 0.9645 & 1.10 \\
\hline
\end{tabular}


Fig. 9 corrosion resistance

\section{Sample \\ Epoxy} $\mathbf{t}=\mathbf{0}$

$\mathbf{t}=\mathbf{3 0}$ days

1

2

3

4
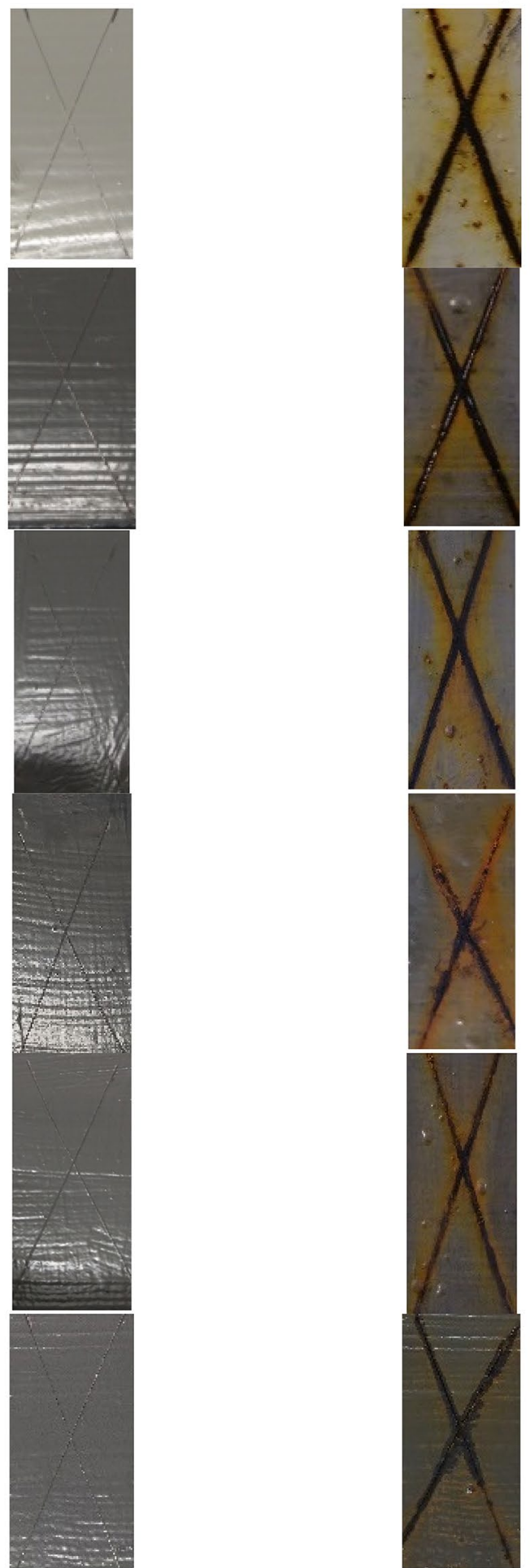

All samples not showed the crystalline peak in XRD curves.

Corrosion resistance was improvement with the carbon black and nanoparticles additions. The additive could reduce the ion attack.
The best results of electromagnetic interference were obtained to the sample in the high concentrations of CB and NP, the good dispersion of fillers increase the attenuation.

\section{SN Applied Sciences}


Acknowledgements FAPERJ (E-026/200.019/2019) and CNPq

\section{Compliance with ethical standards}

Conflict of interest The authors declare that there is no conflict of interest.

Open Access This article is licensed under a Creative Commons Attribution 4.0 International License, which permits use, sharing, adaptation, distribution and reproduction in any medium or format, as long as you give appropriate credit to the original author(s) and the source, provide a link to the Creative Commons licence, and indicate if changes were made. The images or other third party material in this article are included in the article's Creative Commons licence, unless indicated otherwise in a credit line to the material. If material is not included in the article's Creative Commons licence and your intended use is not permitted by statutory regulation or exceeds the permitted use, you will need to obtain permission directly from the copyright holder. To view a copy of this licence, visit http://creativecommons .org/licenses/by/4.0/.

\section{References}

1. Snihirova D, Lamaka SV, Montemor MF (2012) "SMART" protective ability of water based epoxy coatings loaded with $\mathrm{CaCO} 3$ microbeads impregnated with corrosion inhibitors applied on AA2024 substrates. Electrochim Acta. https://doi.org/10.1016/j. electacta.2012.07.102

2. Maron GK, Noremberg BS, Alano JH, Pereira FR, Deon VG, Santos RCR, Freire VN, Valentini A, Lenini N, Carrreno V (2018) Carbon fiber/epoxy composites: effect of zinc sulphide coated nanotube on thermal and mechanical properties. Polym Bull 75(4):1619-1633 https://doi.org/10.1007/s00289-017-2115-y

3. Riaz U, Nwaoha C, Ashraf SM (2014) Recent advances in corrosion protective composite coatings based on conducting polymers and natural resource derived polymers. Prog. Org. Coatings 77(4):743-756

4. Jianhong Y, Deng J, Zhang Q et al (2015) Effects of polysaccharides on the properties of chinese lacquer sap. Prog Org Coatings 78:176-182

5. Monetta T, Acquesta A, Carangelo A, Bellucci F (2018) Considering the effect of graphene loading in water-based epoxy coatings. J Coatings Technol Res. https://doi.org/10.1007/s1199 8-018-0045-8

6. Wei H, Wang Y, Guo J et al (2015) Advanced micro/nanocapsules for self-healing smart anticorrosion coatings. J Mater Chem A. https://doi.org/10.1039/C4TA04791E

7. Da Costa HM, Ramos VD, Da Silva WS, Sirqueira AS (2010) Analysis and optimization of polypropylene (PP)/ethylene-propylenediene monomer (EPDM)/scrap rubber tire (SRT) mixtures using RSM methodology. Polym Test. https://doi.org/10.1016/j.polym ertesting.2010.04.003

8. Montgomery DC, Runger GC (1999) Applied Statistics and Probability for Engineers, $2^{\circ}$. John Wiley \& Sons Inc, New York

9. Cossa MM, Sirqueira AS, Soares BG (2009) Development of thermoplastic elastomers vulcanized (TPV) with polypropylene waste tire. I - Factorial design experiments. Polimeros 19(3):190-195

10. Montemor MF (2016) Hybrid nanocontainer-based smart selfhealing composite coatings for the protection of metallic assets. In: Smart Composite Coatings and Membranes: Transport,
Structural, Environmental and Energy Applications. Woodhead publishing series in composites science and Engineering, pp 183-209. https://doi.org/10.1016/B978-1-78242-283-9.00007-5

11. Córdoba LC, Montemor MF, Coradin T (2016) Silane/TiO 2 coating to control the corrosion rate of magnesium alloys in simulated body fluid. Corros Sci 104:152-161. https://doi.org/10.1016/j. corsci.2015.12.006

12. da Sirqueira AS, Teodoro Júnior D, da Coutinho MS et al (2016) Rheological behavior of acrylic paint blends based on polyaniline. Polímeros. https://doi.org/10.1590/0104-1428.2178

13. Said O, Karasu S, Tahsin M, Karaman S (2015) Three interval thixotropy test (3ITT) in food applications: A novel technique to determine structural regeneration of mayonnaise under different shear conditions. FRIN 70:125-133. https://doi. org/10.1016/j.foodres.2015.02.002

14. Voigt MM, MacKenzie RCl, King SP, Yau CP (2012) Gravure printing inverted organic solar cells: the influence of ink properties on film quality and device performance. Sol Energy Mater Sol Cells 105:77-85. https://doi.org/10.1016/j.solmat.2012.04.025

15. Maranzano BJ, Wagner NJ (2000) Thermodynamic properties and rheology of sterically stabilized colloidal dispersions. Rheol acta 39(5):483-494

16. Jansseune T, Mewis J, Moldenaers P et al (2000) Rheology and rheological morphology determination in immiscible twophase polymer model blends. J Non-newtonian Fluid Mechanics 93:153-165

17. Martys NS, George WL, Lootens BCD (2010) A smoothed particle hydrodynamics-based fluid model with a spatially dependent viscosity : application to flow of a suspension with a non-Newtonian fluid matrix. Rheol acta 49(10):1059-1069. https://doi. org/10.1007/s00397-010-0480-7

18. Boufarguine M, Renou F, Nicolai T, Benyahia L (2010) Droplet deformation of a strongly shear thinning dense suspension of polymeric micelles. Rheol acta 49(6):647-655. https://doi. org/10.1007/s00397-009-0424-2

19. Seo HW, Kim YJ, Kim S et al (2018) Nanoplatelet reinforcement of cavity cell walls in polymer foams using carbon dioxide supercritical fluid. J Appl Polym Sci. https://doi.org/10.1002/ app. 46615

20. Malkin A, Kulichikhin V, Ilyin S (2017) A modern look on yield stress fluids. Rheol Acta 56(3):177-188. https://doi.org/10.1007/ s00397-016-0963-2

21. Rodd AB, Dunstan DE, Ross-murphy SB, Boger DV (2001) Dependence of linear viscoelastic critical strain and stress values on extent of gelation for a thermally activated gelling system. Rheol acta 40(1):23-29

22. Oishi CM, Thompson RL (2016) Transient motions of elasto-viscoplastic thixotropic materials subjected to an imposed stress field and to stress-based free-surface boundary conditions. Int J Eng Sci 109:165-201. https://doi.org/10.1016/j.ijengsci.2016.08.004

23. Coussot $P$ (2018) Slow flows of yield stress fluids : yielding liquids or flowing solids? Rheol acta 57(1):1-14

24. Bayani M, Ehsani M, Khonakdar HA et al (2017) An investigation of $\mathrm{TiO}_{2}$ nanoparticles effect on morphology, thermal, and mechanical properties of epoxy/silica composites. J Vinyl Addit Technol 23:E216-E221. https://doi.org/10.1002/vnl.21558

25. Mason RL, Gunst RF, Hess JL (2003) Statistical design and analysis of experiments. Wiley, New York

26. Shah DA, Madden LV (2014) Nonparametric Analysis of Ordinal Data in Designed Factorial Experiments. Phytopathology 94(1):33-43. https://doi.org/10.1094/PHYTO.2004.94.1.33

27. Dannert R, Winter HH, Sanctuary R, Baller J (2017) Influence of suspension viscosity on Brownian relaxation of filler particles. Rheol acta 56(7-8):615-622. https://doi.org/10.1007/s0039 7-017-1019-y 
28. Hyun K, Wilhelm M, Klein CO et al (2011) Progress in Polymer Science A review of nonlinear oscillatory shear tests : Analysis and application of large amplitude oscillatory shear ( LAOS ). Prog Polym Sci 36:1697-1753. https://doi.org/10.1016/j.progp olymsci.2011.02.002

29. Mewis J, Wagner NJ (2009) Thixotropy. Adv Colloid Interface Sci 148:214-227. https://doi.org/10.1016/j.cis.2008.09.005

30. Riabtseva A, Kaberov LI, Noirez L et al (2018) Structural characterization of nanoparticles formed by fl uorinated poly (2- oxazoline ) -based polyphiles. Eur Polym J 99:518-527. https://doi. org/10.1016/j.eurpolymj.2018.01.007

31. Blanco-cardenas A, Mart JG, Ram E et al (2018) Dispersion and exfoliation of nanoclays in itaconic acid funcionalized LDPE by ultrasound treatment. J Appl Polym Sci 46260:1-10. https://doi. org/10.1002/app.46260

32. Shiravand F, Hutchinson JM, Calventus Y (2016) A novel comparative study of different layered silicate clay types on exfoliation process and fi nal nanostructure of trifunctional epoxy nanocomposites. Polym Test 56:148-155. https://doi.org/10.1016/j. polymertesting.2016.10.007

33. Qiu M, Zhang Y, Wen B (2018) Facile synthesis of polyaniline nanostructures with effective electromagnetic interference shielding performance. J Mater Sci Mater Electron 29(12):10437-10444

34. Lakshimi RV, Yoganandan G, Mohan AVN, Basu BJ (2014) Effect of surface pretreatment by silanization on corrosion protection of AA2024T3 alloy by sol-gel nanocomposite coating. Surf Coat Technol 240:353-360

Publisher's Note Springer Nature remains neutral with regard to jurisdictional claims in published maps and institutional affiliations. 